\title{
Organic-inorganic hybrid nano-particles: Surface
} characteristics and interactions with a polyester resin

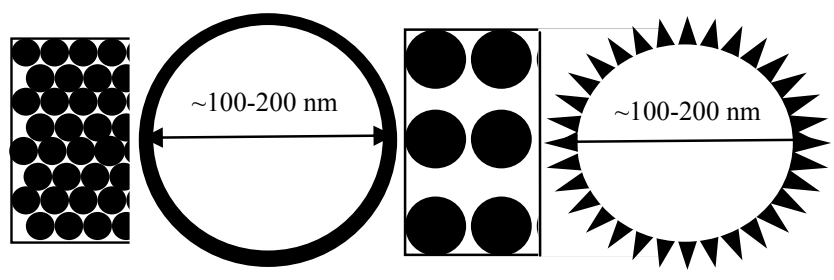




\section{Organic-inorganic hybrid nano-particles: Surface}

\section{characteristics and interactions with a polyester resin}

Authors

David A. Jesson ${ }^{a}$, Marie-Laure Abel ${ }^{a}$, John N. Hay ${ }^{b}$, Paul A. Smith ${ }^{a}$ and John F. Watts ${ }^{a^{*}}$

${ }^{\mathrm{a} U n i S}$ Materials Institute and School of Engineering, ${ }^{\mathrm{b}}$ UniS Materials Institute and School of Biomedical and Molecular Sciences, University of Surrey, Guildford Surrey GU2 7XH UK,

AUTHOR EMAIL ADDRESS (Word Style "BI_Email_Address")

RECEIVED DATE (to be automatically inserted after your manuscript is accepted if required according to the journal that you are submitting your paper to)

TITLE RUNNING HEAD

Interactions of Hybrid Nano-Particles

CORRESPONDING AUTHOR FOOTNOTE

John F. Watts, School of Engineering (Mail Stop H6), University of Surrey, Guildford, Surrey, UK, GU2 7XH Tel: 00441483689617 Fax: 00441483686291 e-mail: j.watts@surrey.ac.uk 


\section{ABSTRACT}

Organic-inorganic hybrid nano-particles, derived from silica precursors with different organic functionalities (methyl, ethyl, vinyl and phenyl) synthesized via a modified Stöber method have been investigated. These particles are intended as modifiers for polymers and polymer matrix composites. Therefore the characteristics of a polyester matrix have also been determined and the likely interactions with the particles have been proposed. Particles have been characterized using inverse gas chromatography (IGC), x-ray photoelectron spectroscopy (XPS) and infra-red spectroscopy (FT-IR). The particles show two different sets of characteristics, with methyl, ethyl, and vinyl modified silicas showing one type of behavior and the phenyl modified silica behaving rather differently. The methyl, ethyl and vinyl groups exhibit the appearance of uniform coverage, as they are comparatively small and tightly packed, which will prevent interaction of matrix resin with retained silanol groups. The phenyl group, which is comparatively large, is not able to pack as closely, which results in a reduction of the presence and availability of silanol groups, compared to an unmodified fumed silica, but not complete inaccessibility as far as the matrix resin is concerned.

\section{KEYWORDS}

Organic-inorganic hybrids, nano-particles, IGC, XPS, silica, polyester, nano-composites,

\section{MANUSCRIPT TEXT}

\section{INTRODUCTION}

In recent years, organic-inorganic hybrids have been developed as potential solutions to a wide array of problems including sensors ${ }^{1}$ and lasers ${ }^{2,3}$. Organically modified silicas (ormosils) are one type of organic-inorganic hybrid ${ }^{1}$. Work is currently underway to determine the efficacy of a range of ormosils 
(in nano-particulate form) as modifiers for polymers and polymer matrix composites ${ }^{4-7}$. However, to understand the effect that the ormosils have on the polymer matrix it is important to appreciate the interaction between the ormosils and the matrix. In a previous paper, the adsorption of the polyester on to commercial, ethyl modified and phenyl modified silicas was described. The adsorption of the polyester onto the commercial silica and phenyl ormosil appeared to produce Langmuir-type isotherms, whereas those produced from the ethyl ormosil were more complicated and suggested a two stage adsorption process. ${ }^{6}$. The current study presents an examination of the surface characteristics of four types of ormosil (methyl, ethyl, vinyl and phenyl modified silicas), a commercial fumed silica (of similar size to the nano-particulate ormosils) and a commercial polyester resin (both in cured and uncured form). The interaction of the polyester with the nano-particles is also discussed. The aim of the study is to derive data such as the surface free energy, the energy of adsorption, the enthalpy of adsorption, and Lewis acceptor and donor numbers of the materials used, from IGC data. This work is supported by XPS analysis of the samples (to assure that the surfaces of the samples are not modified through chemisorption of probes used in the testing and that the sample is not degraded during the conditioning process) and TGA (to determine the stability of the particles over the temperature range of investigation). IGC is widely used in the context of composite materials, to investigate silica fillers ${ }^{8}$ and glass $^{8}$, carbon $^{9}$ and aramid $^{10}$ fibres and also to investigate nano-scale materials ${ }^{11,12}$. In the current research, XPS has also been used to examine the depth and the coverage of the organic layer and IR spectroscopy has been used to examine the types of bonding present.

\section{EXPERIMENTAL}

Methyl, ethyl, vinyl and phenyl modified silica nanoparticles (all are sub $200 \mathrm{~nm}$ diameter as shown in Table 1) were produced using a modified Stöber (hydrolytic) route ${ }^{4}$. A commercial fumed silica (HDK N20, Wacker) used as a thixotropic agent in the production of a commercial polyester resin which is a matrix system under investigation was used as a reference. HDK N20 is produced by flame 
hydrolysis. Primary particles are $\sim 10 \mathrm{~nm}$ in diameter, but during the production process these particles quickly form aggregates of $100-500 \mathrm{~nm}$. In the resin system these will then tend to agglomerate into clusters 10-50 $\mu \mathrm{m}$ in size. The resin used in the work described in this paper was based on a commercial unsaturated polyester resin (Crystic 2-406PA, Scott-Bader), but without the addition of the usual fumed silica thixatrope. Analysis was carried out on this resin in both the uncured and cured states. The cure process for this resin is initiated by methyl ethyl ketone peroxide (Catalyst M, ScottBader) and is fully cured after 24 hours at room temperature. A post-cure of $80{ }^{\circ} \mathrm{C}$ for 3 hours is advised and has been used in the current work.

The thermodynamic properties determined from the IGC data are the dispersive component of the surface free energy, $\gamma_{s}{ }^{d}$; the free energy of adsorption of probe molecules due to both dispersive forces and acid-base interactions; the enthalpy of adsorption of a range of chemicals onto the candidate surfaces; and the acid-base constants $\mathrm{K}_{\mathrm{A}}$ and $\mathrm{K}_{\mathrm{D}}$ and the surface character parameter, $\mathrm{S}_{\mathrm{C}}$, which is defined as the ratio of $\mathrm{K}_{\mathrm{D}}$ and $\mathrm{K}_{\mathrm{A}}{ }^{13}$. Experiments were carried out using an Agilent 6890 gas chromatograph with a flame ionization detector. In this case the combustion of an $\mathrm{H}_{2}$ plus air mixture formed the flame, with $\mathrm{H}_{2}$ produced by the electrolysis of distilled water via an ancillary unit (Agilent 5184-3503). The stainless steel columns used in these experiments followed IGC convention and were $32 \mathrm{~cm}$ long and 1/8 inch $(\sim 3.2 \mathrm{~mm})$ outer diameter. Columns were filled using the 'tap-and-fill' method using aggregates of 200-300 $\mu \mathrm{m}$. These aggregates were produced by crushing pellets that were formed by subjecting a sample of the particles to pressure, and then sieving to remove the required size fraction. The marker probe used for the IGC experiments was methane (Fluka, GC), the specific probes were a series of alkanes pentane (Aldrich, HPLC), hexane (Aldrich, HPLC), heptane (Fluka, GC), octane (Aldrich, HPLC), nonane (Aldrich, HPLC) and decane (Aldrich, HPLC). Eight polar probes were used; dioxane (Fluka, GC) has a completely basic character, whilst chloroform (Sigma-Aldrich, HPLC) and dichloromethane (Aldrich, HPLC) have completely acidic characters. Other probes are nominally acidic (tert-butanol, Fluka GC) or basic (diethylether, BDH AnalaR, methyl acetate, Fluka GC and 
tetrahydrofuran, Sigma-Aldrich HPLC)), whilst having minor basic or acidic characteristics respectively. Carbon tetrachloride (Prolabo) has a very small acidic character although it is often considered to be neutral. These probes, together with relevant data, are outlined in Table 2 .

The retention volume $\mathrm{V}_{\mathrm{N}}$ (equation 1) is a function of the flow of the carrier gas and the net retention time $t_{N}$ (where the net retention time is the retention time of the probe $\left(t_{R}\right)$ with reference to a marker probe $\left.\left(\mathrm{t}_{0}\right)\right)$ and is expressed as:

$$
V_{N}=j F t_{N}=\left(\left(\frac{3}{2}\right)\left(\frac{\left(\frac{P_{i}}{P_{o}}\right)^{2}-1}{\left(\frac{P_{i}}{P_{o}}\right)^{3}-1}\right)\right) F t_{(R-0)}
$$

where $\mathrm{j}$ is correction factor relating to the pressure of the system, $\mathrm{F}$ is the carrier gas flow rate and $\mathrm{P}_{\mathrm{i}}$ and $\mathrm{P}_{\mathrm{o}}$ are the column inlet and outlet pressures respectively. It is $\mathrm{V}_{\mathrm{N}}$ that is the experimental variable that is the basis for the determination of the surface properties.

The polyester resin without commercial silica in the uncured form (PEs) was coated onto a support material (Chromosorb, Sigma) for IGC analysis, following the technique of Al-Saigh and Munk ${ }^{14}$. For comparison, a thermoplastic polystyrene (PS) was also examined by IGC. PS should display the same properties when coated on a support material (from a dilute solution) as when it is in a finely divided solid form. Kontominas et $a l^{15}$ reported using this technique with PS whereby thin films of PS were dissolved in THF. An apolar solvent such as toluene is preferred, since this will limit interactions between the solvent and solute: toluene was also to be used to disperse the uncured PE and has been shown to be suitable for this material as well as having been used in a previous study ${ }^{6}$. It was shown however, that the samples produced using this method were too tacky to use, as well as time consuming to produce due to the low volatility of the toluene. Instead chloroform was used with $2 \mathrm{wt} \%$ solutions of the polymers in chloroform. PE contains $\sim 33 \mathrm{wt} \%$ styrene and it was anticipated that this would 
evaporate from solution; this being the case $2.66 \mathrm{wt} \%$ solution was produced to give $2 \mathrm{wt} \%$ of the polyester in solution. Cured PEs was ground and sieved. The 200-300 $\mu \mathrm{m}$ fraction was removed for use. This process was also used for the PS so as to provide a suitable comparison.

XPS was carried out using a Thermo VG Scientific Sigma-Probe using both Al Ka radiation (from a monochromated source) and $\mathrm{Mg} \mathrm{K} \alpha$ radiation (from a twin anode source). Thermo's Avantage 2.18 software was used. The area of analysis was $\sim 500 \mu \mathrm{m}$ in diameter for both the monochromated source and twin anode sources. A pass energy of $150 \mathrm{eV}$ was used for survey spectra ( $0.4 \mathrm{eV}$ step) and $20 \mathrm{eV}$ for high resolution core spectra of the elements of interest (in particular, C1s, O1s and Si2p). The characteristic analysis depth for XPS is usually taken as three times the electron attenuation length (AL) decaying exponentially from the outer surface. By using both sources it is possible to probe in two depth scales $(\mathrm{AlK} \alpha: 3 \mathrm{AL} \approx 9 \mathrm{~nm}, \mathrm{MgK} \alpha 3 \mathrm{AL} \approx 7.5 \mathrm{~nm})$.

The FTIR spectroscopy investigation was carried out with a Perkin-Elmer FTIR 2000 with System 3.0 software, which surveyed between $400-4000 \mathrm{~cm}^{-1}$ in $1 \mathrm{~cm}^{-1}$ steps. Samples were prepared by grinding the particles with potassium bromide $(\mathrm{KBr})$, from which discs were produced, using pressure. No special precautions were taken in the preparation of the discs. Differences in the baseline, i.e. the transmittance recorded for wavenumbers not associated with vibrations, between (a) different parts of the same sample and (b) different samples are likely to be due to differences in the transparency of and between samples. The distribution of ormosil particles in the $\mathrm{KBr}$ and the crystal size of the $\mathrm{KBr}$ particles can have a significant effect upon the transparency of the sample.

\section{RESULTS}

Analysis by Inverse Gas Chromatography 
A number of probes were used to determine characteristics of the materials under investigation. A sequence of alkane probes was used in conjunction with the method of Dorris and Gray ${ }^{16}$ to determine the dispersive component of the surface free energy, calculated using equation 2 :

$$
\gamma_{S}^{d}=\left(\frac{1}{4 \gamma_{\mathrm{CH}_{2}}}\right)\left(\frac{-\Delta G_{\mathrm{CH}_{2}}}{N_{\mathrm{A}} \alpha_{\mathrm{CH}_{2}}}\right)^{2}
$$

$\mathrm{N}_{\mathrm{A}}$ is Avogadro's Number and $\alpha_{\mathrm{CH} 2}$ is the cross sectional area of a methylene group, $6 \AA^{2}=6 \times 10^{-20}$ $\mathrm{m}^{2} . \gamma_{\mathrm{CH} 2}$ is the surface free energy of a solid containing only methylene groups. Originally ${ }^{17}$ this was expressed as:

$$
\gamma_{\mathrm{CH} 2}=35.6+0.058(20-\mathrm{T})
$$

although by IGC convention this is approximated to:

$$
\gamma_{\mathrm{CH} 2}=36.8+0.058 \mathrm{~T}
$$

In both cases the temperature, again by IGC convention, is in degrees Celsius. The parameter $-\Delta \mathrm{G}_{\mathrm{CH} 2}$ is the free energy of adsorption of a methylene group, determined from equation 5 (below) and as such may be determined from the slope of a graph of $\mathrm{RT} \ln \mathrm{V}_{\mathrm{n}}$ vs. the number of carbon atoms. The values for the dispersive component of the surface free energy are presented in Figure 1 (for the ormosil particles, which are compared at different temperatures) and Table 3 (which compares the polymers at $45^{\circ} \mathrm{C}$ ).

$$
-\Delta G_{\mathrm{CH}_{2}}=R T \ln \left(\frac{V_{n+1}}{V_{n}}\right)
$$

where $\mathrm{R}$ is the gas constant, $\mathrm{T}$ is the experimental temperature and $\mathrm{V}_{\mathrm{i}}$ is the retention volume of a given probe. In this instance, $V_{n}$ and $V_{n+1}$ represent two sequential alkanes e.g. n-C5 and n-C6.

The method of Saint Flour and Papirer ${ }^{18}$ was used to determine the acid-base properties of the materials surfaces. A number of other probes were used, these with polar characteristics whether acidic, basic or amphoteric. The values for these characteristics are presented in Table 4 . In addition the enthalpies of adsorption $(\Delta \mathrm{H})$ have been determined for each probe on each ormosil. These values are presented in Table 5. 


\section{Analysis by X-ray Photoelectron Spectroscopy}

XPS has been used to examine the surfaces of the various particles as well as the polyester resin, both in its cured and uncured state. Figure 2 presents examples of the XPS spectra produced, where the XPS spectra of methyl ormosil is compared using the $\mathrm{Al} \mathrm{K \alpha}$ and $\mathrm{Mg} \mathrm{K \alpha}$ sources. Here it can be seen that the intensity of $\mathrm{C} 1 \mathrm{~s}$ to $\mathrm{Si} 2 \mathrm{p}$ is significantly higher when using $\mathrm{Mg} \mathrm{K} \alpha$ rather than $\mathrm{Al} \mathrm{K} \alpha$ radiation. From these analyses a number of properties can be derived. Many attempts have been made to quantify the thickness of carbon layers. Cross and Dewing ${ }^{19}$ have demonstrated the application of an intensity calculation to coated spherical particles:

$$
I_{d}=I_{\infty} e^{\frac{-d}{\lambda \sin \theta}}
$$

where the intensity of the Si2p peak is measured for the commercial silica, $\mathrm{I}_{\infty}$, and for the modified silicas, $I_{d}: \lambda$ is the attenuation length of an Si2p electron through a carbon layer, $d$ is the depth of the carbon layer and $\theta$ is the electron take off angle, relative to the sample. For a planar surface $\theta$ can be accurately defined, but in the case of spherical particles a range of angles will be observed, such that it has been shown that $\sin \theta$ will tend to $0.5^{18,19}$. Thus, the thickness of a carbon overlayer is given by:

$$
d=0.5 \lambda \ln \left(\frac{I_{\infty}}{I_{d}}\right)
$$

Whilst not perhaps a strictly accurate application, since the organic moiety is bonded rather than adsorbed on the surface, this technique can be applied to the ormosils using the commercial silica to determine $\mathrm{I}_{\infty}$. Furthermore, such a model will only apply to a finite, fully dense overlayer, which may not be the case in this study. However, such an approach can be used to estimate the integral amount of 
organic material at the particle surface and the results of such a calculation yield values that are described as the equivalent overlayer thickness. The results of these calculations are presented in Table 6 , together with the constants used. The ratios of $\mathrm{C} / \mathrm{Si}$ and $\mathrm{O} / \mathrm{Si}$ have been determined, from quantitative surface chemical analyses, using both $\mathrm{Al} \mathrm{K} \alpha$ and $\mathrm{Mg} \mathrm{K} \alpha$ sources. It should be recalled that the relative photon energies $(\mathrm{Al} \mathrm{K \alpha}, \mathrm{hv}=1486.6 \mathrm{eV}$ and $\mathrm{Mg} \mathrm{K \alpha} \mathrm{hv}=1253.6 \mathrm{eV})$ lead to a difference in kinetic energies of $233 \mathrm{eV}$ for equivalent core levels. As the depth of analysis in XPS is a function of electron kinetic energy this provides a modest, but useful, depth profiling capability. In the case of the $\mathrm{C} 1 \mathrm{~s}$ electron the analysis depth is some $1 \mathrm{~nm}$ greater in $\mathrm{Al} \mathrm{K \alpha}$ radiation than $\mathrm{Mg} \mathrm{K \alpha}$. XPS data for all samples are presented in Table 7.

\section{Analysis by Fourier Transform Infra Red Spectroscopy}

FTIR spectroscopy has been used to investigate the chemical groups associated with the modified particles and the commercial silica has been used as a benchmark. As expected, there are a number of organic specific bands that relate to the particular ormosils, but as this paper is interested in the effect of the organic functionality on the behavior of the silanol functionality, it is these bands that will be highlighted. Figure 3 presents a FTIR spectrum for the commercial silica and expanded spectra for the two regions (1000-1400 and 3000-3800 $\left.\mathrm{cm}^{-1}\right)$ where the ormosils are compared to the commercial silica. For clarity, assignments are presented separately in Table 8. Bulk silica has a number of bands of interest $\left(1225-1200,1175-1150,1100-1075,805-785 \mathrm{~cm}^{-1}\right)$. If the structure of the silica supports the formation of ring structures (which will have some degree of bond strain) then other bands may be observed. Short silica chains tend to adsorb at around $1050 \mathrm{~cm}^{-1}$ with increasing length leading to a broadening of this band, whilst long-chains have maxima at 1085 and $1025 \mathrm{~cm}^{-1}$. In general then, features in the region $1100-1000 \mathrm{~cm}^{-1}$ will be associated with silica structure, with more detailed determination relying on knowledge of the chemical structure of the particle. It can be seen in Figure $3 \mathrm{~b}$ that features of this region become, in general, more defined with the modification of the silica. This 
is most likely to be a result of the production method. The commercial silica is produced by flame hydrolysis, whilst the ormosils are produced from a sol-gel technique. This undoubtedly has some effect on the silica structure: the greater definition in this region points to a less amorphous structure. Assignment of some of these bands is straight forward, as described above. Others are a result of, or are distorted by inter-particulate interaction, which is described in more detail in the next section.

\section{DISCUSSION}

In the previous section, results from the IGC, XPS and FT-IR experiments were presented. The following discussion will integrate these various results to produce a hypothesis regarding the effect of organic modification on the surface properties of silica particles.

The experimental results presented in this paper can be considered in two parts. The first part deals with thermodynamic properties and the second deals with the surface chemistry of the particles. By considering both parts together it is possible to discuss the potential interaction of the particles with a polyester resin.

The thermodynamic properties, as determined by IGC, show several differences between the ormosils and commercial silica. For example, the surface free energy is smaller for the modified silicas. It is interesting to note that the vinyl ormosil yields the lowest values of $\gamma_{\mathrm{s}}{ }_{\mathrm{s}}^{\mathrm{d}}$. A difference in dispersive contribution to the surface energy may be related to the polarizability of the functional group (all else identical). According to the NIST database (as of 26/01/2005 - http://srdata.nist.gov/gateway/ keyword: polarizability), the polarizability of ethylene and ethane is equal to respectively 4.188 and $4.288 \AA^{3}$. It seems unlikely that such a small difference may be sufficient to explain a variation of approximately $10 \mathrm{~mJ} \mathrm{~m}^{-2}$ between the vinyl and ethyl functionalized ormosil. The fact that the vinyl value is so much lower indicates significant surface energy minimization of this type of ormosil, possibly as a result of the shorter $\mathrm{C}=\mathrm{C}$ double bond or of a different conformation. More importantly there is a general decrease in both the surface acidity and basicity (Table 4). Evidence of any surface acidity points to the presence of a modest number of retained silanol groups "visible" to the molecular probe, i.e. incomplete coverage of the surface by the organic functionality. The exception to this is the 
phenyl modified silica where the surface basicity increases (as a result of the stable donation of delocalized electron pairs from the phenyl moieties) combined with the highest surface acidity of any of the modified silicas, although this surface acidity is still much lower than that observed in the commercial silica. This is shown in the acid-base properties measured by IGC. These results show that the acidic component, measured by $\mathrm{K}_{\mathrm{A}}$, decreases significantly in the case of the modified silicas, but that the phenyl modified silica has the largest value of $\mathrm{K}_{\mathrm{A}}$, which is about $42 \%$ that of the commercial silica. The next largest value is that of the vinyl modified silica at about $21 \%$, with the methyl and ethyl modified silicas presenting values that are less than $10 \%$ of the commercial silica. The estimates above are from the measurements made at $100{ }^{\circ} \mathrm{C}$. It may be remembered from the experimental section that a surface character parameter $\left(\mathrm{S}_{\mathrm{c}}\right)$ is defined as the ratio $\mathrm{K}_{\mathrm{D}} / \mathrm{K}_{\mathrm{A}}$. Whilst it is necessary to remember that a surface with few interacting sites may give the same value for $S_{c}$ as one with many interacting sites, it is a useful parameter in that it can show the dominating character of the surface. As can be seen from the data of Table 4, most ormosil samples exhibit a basic behavior with strongest basicity observed in the phenyl ormosil. As may be anticipated the HDK N20 shows the strongest acidity. An attempt to correlate $S_{c}$ to $\gamma_{s}{ }^{d}$ was not successful. This indicates that an increase in $\gamma_{s}{ }^{d}$ for these materials does not arise solely from the changing acido-basic properties of the ormosils. As expected the ormosils show a temperature dependence such that the level of interaction decreases with increasing temperature. The enthalpies of adsorption showed some variation with surface modification. The enthalpies of adsorption of the probes used to characterize the surface properties (Table 5) were consistent with physisorption, which shows that the organic modification is stable and remains unmodified by the probes used. This is deduced from the values of the enthalpies which for the most part lie in the region (less negative than $84 \mathrm{kJmol}^{-1}$ ) which is usually attributed to physisorption. Some of the values are greater than this (somewhat arbitrary) limit. However, as mentioned previously, the probes show a temperature dependence such that the increase in temperature leads to a decrease in interaction. If chemisorption were taking place it is more likely that interaction would increase.

The surface chemistry of the particles was assessed using XPS and FT-IR. As expected the amount of organic material in the outer layer changes slightly for different alkyl modified silicas. XPS shows that the modified particles have an organic layer which shows little variation for the alkyl modified silicas, whilst in the case of the phenyl modified silica the integral carbon thickness increases significantly. This is supported by FT-IR which shows that whilst there are still silanol groups present these are more disperse. This is indicated by the decrease in the peak at approximately $\sim 3450 \mathrm{~cm}^{-1}$, which is produced 
from inter-silanol group hydrogen bonding. In the case of the commercial silica there is a considerable quantity of silanol groups (at the surface) which are hydrogen bonding, primarily to adsorbed water. This hydrogen bonding decreases in the case of the modified silicas. In the first instance, when we consider Figure 3c, it is surprising that there should be any evidence of water adsorption at all and in fact the feature due to the methyl modified silica is nearly as large as that due to the commercial silica. On further consideration, however, as the methyl group is the smallest organic group of those used (and indeed available), it is possible for water to hydrogen bond to silanol groups. There will also be hydrogen bonds due to self-association amongst the adsorbed water molecules. Hence, the reduction of the hydrogen bonding observed in the other ormosils can be attributed to the further strain on the hydrogen bonding between the adsorbed water and the retained silanol groups as a result of the increasing distance between the groups. The hypothesis that follows from the above is that since the phenyl group is larger than that of the other organic groups, this leads to greater separation of these groups on the surface of the particles. Hence, it might be expected that the phenyl modified silica might see hydrogen bonding amongst residual silanol groups as well as with adsorbed water. This is undoubtedly true, but not to the level that might at first be thought. The organic groups are present at the surface instead of a number of silanol groups. In the case of the phenyl modified silica there will be more retained silanol groups but the potential to form hydrogen bonds will be significantly reduced. It is significant that the phenyl modified silica has a much more distinct peak at $3620 \mathrm{~cm}^{-1}$ than any of the other particles with the exception of the vinyl modified silica. It is probable that this is a peak displaced from $3747 \mathrm{~cm}^{-1}$ representing isolated silanol groups ${ }^{21}$.

In a previous paper ${ }^{6}$ the adsorption of the polyester onto ormosil particles was studied by ToF-SIMS and adsorption isotherms were derived. This work concentrated on the commercial silica and the ethyl and phenyl modified silicas. This work further supports the hypothesis that there is some similarity between the phenyl modified silica and the commercial silica and that the other ormosils behave differently having a lower capacity for the polyester resin. Here it was shown that there is a 
conformational change in the adsorbed polyester when it is adsorbed onto the ethyl modified silica, but this conformational change is not observed when dealing with the commercial or phenyl modified silicas.

As has been previously mentioned in this paper, the depth of analysis varies with x-ray source energies. Hence, by comparing the intensities of elements determined using different $\mathrm{x}$-ray sources it is possible to comment on the morphology of an overlayer. In this particular case it is possible to show that the methyl, ethyl and vinyl modified silicas form a coverage that can be considered uniform, whilst the phenyl functionalities are more disperse, and do not form a complete coverage of the surface. This determination is made by examining the data in Table 7. Here it can be seen that, in general, excepting the phenyl ormosil, there is a significant difference in the intensities of the $\mathrm{C}, \mathrm{O}$ and $\mathrm{Si}$ peaks between the $\mathrm{Al} \mathrm{K \alpha}$ and $\mathrm{Mg} \mathrm{K} \alpha$ sources. This feature is clearly seen in the XPS survey spectra of Figure 2. When the spectrum is excited by $\mathrm{Al} \mathrm{K \alpha}$ radiation (Figure 2a) the $\mathrm{C} 1 \mathrm{~s}$ and $\mathrm{Si} 2 \mathrm{p}$ peaks are of approximately equal intensity. On switching to $\mathrm{Mg} \mathrm{K \alpha}$ radiation (Figure 2b) however, the kinetic energy of the outgoing electrons is reduced by $233 \mathrm{eV}$ and the depth of analysis by $1 \mathrm{~nm}$. The spectrum now takes a very different form as can be seen from Figure $2 \mathrm{~b}$, with the $\mathrm{C} 1 \mathrm{~s}$ intensity approximately twice that of the Si2p. Qualitatively this indicates that the organic moieties of the ormosils are present as a surface phase rather than distributed uniformly throughout the bulk of the individual particles. In the case of the phenyl ormosil the difference between the two sources is minor. If a dispersed morphology is considered, it can be seen that the intensities due to two different sources will be similar, as the substrate and overlayer will be interrogated in a similar manner by both sources. In the case of a complete overlayer, the $\mathrm{Mg} \mathrm{K \alpha}$ source, which will not have such a deep a sampling depth, and will show a greater intensity for the overlayer and a lesser intensity for the substrate than is the case with the $\mathrm{Al} \mathrm{K \alpha .}$ 
By combining the results of the thermodynamic and chemical analyses it is possible to present a model of the surface of the modified silicas. The data presented is consistent with a situation where the organic modification by the methyl, ethyl and vinyl groups can be considered as a uniform overlayer. The phenyl modified silica is more disperse. It can be visualized that the alkyl modifications pack comparatively easily and therefore are present in sufficient density that they can be considered as a complete layer. The phenyl rings being larger find it more difficult to pack closely together. In the case of the phenyl modified silicas the -SiOH surface groups have not been completely obscured and so these groups still have some influence on the surface chemistry, although this influence is diminished when considered with respect to the commercial silica. Based on the above information it is possible to compare the difference between the phenyl modified silica and the other modified silicas. Figure 4a presents the surface of the methyl, ethyl and vinyl modified silicas, and compares this to the uniform monolayer (Figure 4b) whilst Figure 4c presents the surface of the phenyl modified silica, and compares this to the raspberry-seed model ${ }^{22,23}$ (Figure 4d), where the surface modification may be considered as discrete areas on the surface.

Jensen $^{24}$ presented an examination of the Lewis theory of acids and bases in terms of molecular orbital (MO) theory. Within MO theory, there are three possible states: non-bonding, n; anti-bonding, a, and bonding, b. Interactions are also considered in terms of the type of bonding; single, $\sigma$, and double, $\pi$, bonds. A matrix of the possible electron-pair donor-acceptor (EPDA) adducts is considered in Table 9. The polyester and the functional groups of silica and modified silicas can be considered in these terms. Directly, there are five types of electron pair donor or acceptor sites on the polyester and by the standard definitions there are three types of functionality associated with the silica that can be considered (Table 10). Properly, the ester group should be considered as one, although for completeness it is presented as both a single group as well as being considered separately as a ketonic oxygen and an ether linkage. Oxygen, being more electronegative than carbon, has the ability to draw electrons away from bonded carbons. In theory this should make the carboxyl carbon extremely 
positive and in turn make this an EPA (electron pair acceptor). Research on PMMA has shown that the ketonic oxygen is much more basic than the ether oxygen, as well as being more accessible ${ }^{25}$. This means that whilst the situation is as described, it requires an extremely strong base, such as pyridine, to produce an acid-base interaction $^{25}$. This being the case the following assumptions can be made. Firstly, the ester group will only interact with the particles as an EPD (electron pair donor) and secondly the ester group will only interact with the particles through the ketonic oxygen.

The only ormosils that have any direct acido-basic characteristic are the vinyl and phenyl modified silicas and of these two, the vinyl is considerably weaker than the phenyl (Table 4). Since silicon is less electronegative than carbon it might be possible for the organic moieties to take on a slight EPD characteristic, although this would be even weaker than that of the vinyl group. Apart from this, the methyl and ethyl functionalities are apolar.

This analysis suggests that, in the case of the modified silicas, there are few opportunities for the formation of EPDA adducts whilst the commercial silica has the opportunity to form $n-\sigma^{*}$ and $\pi-\sigma^{*}$ adducts. As has been argued previously, the phenyl modified silica leaves some silanol groups exposed at the surface allowing limited bonding with the polyester. In the case of the phenyl modified silica, it is possible that there is $\pi \rightarrow \pi^{*}$ interaction between the phenyl moiety on the silica and the phenyl rings of the polyester resin, as is found, for example, between graphene sheets. This is, however, unlikely to be a dominant bonding mode, for reasons of stereochemistry: aligning the phenyl rings would prove difficult due both to the position of the phenyl ring within the polyester chain and to the arrangement of the phenyl rings on the surface of the phenyl modified silica. In the case of the other modified silicas, it is possible for bonding (through dispersion interactions due to instantaneous dipoles) to occur between the organic functionalities of the particles and the methylene sites of the polyester resin (that is the carbons which are not part of double bonds or ester linkages etc.). 
The possible specific interactions between the polyester and the various silicas are considered in a schematic format in Figure 5. Here it can be seen that the commercial silica is able to form a number of different EPDA adducts, whilst the phenyl groups have the opportunity only with amphoteric -OH groups at either end of the chain. These bonds are likely to be much weaker than any interaction involving a silanol group. Finally, the methyl modified silica represents the other ormosils; these cannot form any EPDA adducts.

The modified silicas examined in this paper are being investigated as modifiers for polymers. The surface properties investigated in the present work are likely to have a significant effect on the nature and extent of interfacial bonding between the various nano-particles and a polyester matrix. This will influence the mechanical properties of a polyester matrix containing nano-particles additions, specifically the toughness (energy adsorption during crack propagation). Future work will report on the toughness of modified systems.

\section{CONCLUSIONS}

It is clear that organic modification of silica particles has led to a marked difference in the thermodynamic properties and surface chemistry of these particles. In turn this has changed the degree of interaction of the particles with a polyester resin. Whilst the commercial silica bonds strongly to the resin, there is a much reduced level of interaction between the modified silicas and the polyester. The phenyl modified silica, principally through accessible silanol groups is able to interact with the polyester more strongly than the other ormosils, but this interaction is still much less than would be observed with the commercial silica. The effect that this change in interaction has on the toughness of polyester nano-composites (that is polyester modified by ormosil nano-particles) will be presented in a paper currently in preparation. 


\section{ACKNOWLEDGMENTS}

The authors thank the Engineering and Physical Sciences Research Council (EPSRC) and the MoD Joint Grants Scheme for their joint funding of this project, Scott-Bader for their support, Dr. Steven Hinder for assistance with the XPS analyses and Dr. Gabi Wagner for assistance and valuable discussions regarding the FT-IRS analyses.

\section{FIGURE CAPTIONS}

Table 1 - Diameters of Ormosil Particles

\begin{tabular}{|c|c|c|}
\hline \multirow{2}{*}{$\begin{array}{c}\text { Modified } \\
\text { Silica }\end{array}$} & \multicolumn{2}{|c|}{$\begin{array}{c}\text { Average particle diameter/ } \\
\text { nm }\end{array}$} \\
\cline { 2 - 4 } & TEM & SEM \\
\hline methyl & $85 \pm 10$ & $78 \pm 9$ \\
\hline ethyl & $65 \pm 14$ & $65 \pm 7$ \\
\hline vinyl & $106 \pm 19$ & $165 \pm 18$ \\
\hline phenyl & $148 \pm 21$ & $76 \pm 9$ \\
\hline
\end{tabular}

From Arkhireeva and Hay ${ }^{4}$ averaged over 100-150 particles

Table 2 - Chemical information for IGC Probes

\begin{tabular}{|c|c|c|c|c|c|}
\hline Probe & Abbreviation & $\begin{array}{c}\text { Main } \\
\text { acido-basic }\end{array}$ & $\mathrm{AN}^{*} /$ & $\mathrm{DN} /$ & $\mathrm{T}_{\mathrm{b}} /{ }^{\circ} \mathrm{C}$ \\
\hline
\end{tabular}




\begin{tabular}{|c|c|c|c|c|c|}
\hline & & Character & $\mathrm{kcal} \mathrm{mol}^{-1}$ & $\mathrm{kcal} \mathrm{mol}^{-1}$ & \\
\hline pentane & $\mathrm{n}-\mathrm{C5}$ & apolar & - & - & 36.1 \\
\hline hexane & n-C6 & apolar & - & - & 68.7 \\
\hline heptane & $\mathrm{n}-\mathrm{C} 7$ & apolar & - & - & 98.4 \\
\hline octane & $\mathrm{n}-\mathrm{C} 8$ & apolar & - & - & 125.7 \\
\hline nonane & n-C9 & apolar & - & - & 150.8 \\
\hline decane & $\mathrm{n}-\mathrm{C} 10$ & apolar & - & - & 174.1 \\
\hline dichloromethane & $\mathrm{CH}_{2} \mathrm{Cl}_{2}$ & acidic & 16.3 & 0 & 40 \\
\hline chloroform & $\mathrm{CHCl}_{3}$ & acidic & 22.6 & 0 & 61.2 \\
\hline carbon tetrachloride & $\mathrm{CCl}_{4}$ & neutral & 2.9 & 0 & 77 \\
\hline tert-butanol & ter-but & acidic & - & - & 83 \\
\hline diethylether & DEE & basic & 5.9 & 80.3 & 34.6 \\
\hline methyl acetate & Me-Acet & amphoteric & 6.7 & 69.0 & \\
\hline tetrahydrofuran & THF & basic & 2.1 & 83.7 & 66 \\
\hline dioxane & $\mathrm{DXN}$ & basic & 0 & 61.9 & 101 \\
\hline
\end{tabular}

Table $3-\gamma_{\mathrm{s}}^{\mathrm{d}}$ of Polymers at $\mathrm{T}=45^{\circ} \mathrm{C}$

\begin{tabular}{|c|c|}
\hline Polymer & $\gamma_{\mathrm{s}}^{\mathrm{d}} / \mathrm{mJm}^{-2}$ \\
\hline PEs, cured, ground & 31.9 \\
\hline PEs, coated chromosorb & 31.3 \\
\hline PS, ground & 30.5 \\
\hline PS, coated chromosorb & 29.3 \\
\hline
\end{tabular}

Table 4 - Acid-Base Characteristics for a Range of Materials investigated by IGC

\begin{tabular}{|c|c|c|c|}
\hline Material & $100^{\circ} \mathrm{C}$ & $125^{\circ} \mathrm{C}$ & $150^{\circ} \mathrm{C}$ \\
\hline
\end{tabular}




\begin{tabular}{|c|c|c|c|c|c|c|c|c|c|}
\hline & $\mathrm{K}_{\mathrm{A}}$ & $\mathrm{K}_{\mathrm{D}}$ & $\mathrm{S}_{\mathrm{C}}$ & $\mathrm{K}_{\mathrm{A}}$ & $\mathrm{K}_{\mathrm{D}}$ & $\mathrm{S}_{\mathrm{C}}$ & $\mathrm{K}_{\mathrm{A}}$ & $\mathrm{K}_{\mathrm{D}}$ & $\mathrm{S}_{\mathrm{C}}$ \\
\hline HDK N20 & 0.82 & 0.36 & 0.43 & 0.73 & 0.29 & 0.40 & 0.65 & 0.28 & 0.44 \\
\hline methyl & 0.05 & 0.04 & 0.69 & 0.05 & 0.08 & 1.74 & 0.04 & 0.09 & 2.19 \\
\hline ethyl & 0.08 & 0.15 & 2.02 & 0.03 & 0.18 & 6.00 & 0.01 & 0.03 & 3.00 \\
\hline vinyl & 0.18 & 0.13 & 0.72 & 0.11 & 0.05 & 0.43 & 0.10 & 0.01 & 0.11 \\
\hline phenyl & 0.35 & 0.60 & 1.69 & 0.15 & 0.26 & 1.74 & 0.19 & 0.29 & 1.55 \\
\hline $\begin{array}{c}\text { PEs (uncured, coated } \\
\text { Chromosorb) }\end{array}$ & 0.46 & 2.77 & 5.96 & 0.37 & 3.03 & 8.20 & 0.47 & 3.03 & 6.40 \\
\hline PEs (cured) & 0.13 & 1.36 & 10.41 & 0.13 & 1.61 & 12.42 & 0.15 & 0.90 & 6.17 \\
\hline \begin{tabular}{c} 
PS \\
\hline
\end{tabular} & 0.31 & 2.69 & 8.56 & 0.27 & 2.71 & 10.05 & 0.28 & 2.67 & 9.39 \\
\hline $\begin{array}{c}\text { PS (coated } \\
\text { chromosorb) }\end{array}$ & 0.53 & 1.10 & 2.09 & 0.52 & 1.78 & 3.40 & 0.53 & 1.29 & 2.45 \\
\hline
\end{tabular}


Table 5 - Enthalpies of Adsorption $\left(\Delta \mathrm{H} / \mathrm{kJmol}^{-1}\right)$ of IGC Probes Onto a Range of Substrates

\begin{tabular}{|c|c|c|c|c|c|c|c|c|c|}
\hline \multirow[t]{2}{*}{ Probe } & \multirow{2}{*}{$\begin{array}{l}\text { HDK } \\
\text { N20 }\end{array}$} & \multicolumn{4}{|c|}{ ormosils } & \multirow{2}{*}{$\begin{array}{l}\text { Crystic } \\
2-406 \mathrm{PA}\end{array}$} & \multirow{2}{*}{$\begin{array}{l}\text { Poly } \\
\text { (styrene) }\end{array}$} & \multirow{2}{*}{\begin{tabular}{|l|} 
Crystic \\
2-406PA \\
coated ch
\end{tabular}} & \multirow{2}{*}{$\begin{array}{l}\text { Poly } \\
\text { (styrene) }\end{array}$} \\
\hline & & methyl & ethyl & vinyl & phenyl & & & & \\
\hline$n-C 5$ & 34.7 & 47.8 & 37.8 & 31.8 & 42.4 & - & - & 18.5 & 21.8 \\
\hline n-C6 & 41.2 & 54.8 & 43.4 & 36.2 & 48.9 & - & - & 66.9 & 25.2 \\
\hline n-C7 & 47.0 & 61.9 & 48.8 & 39.8 & 54.2 & 35.6 & 21.5 & 120.9 & 30.2 \\
\hline$n-C 8$ & 54.1 & 68.7 & 54.5 & 46.1 & 60.1 & 33.8 & 22.2 & 104.9 & 35.3 \\
\hline n-C9 & 49.0 & 55.4 & 60.0 & 51.7 & 65.7 & 33.8 & 31.4 & 112.8 & - \\
\hline $\mathrm{n}-\mathrm{C} 10$ & 56.0 & 61.1 & 65.8 & 56.7 & 71.3 & 38.1 & 36.7 & - & - \\
\hline $\mathrm{CH}_{2} \mathrm{Cl}_{2}$ & 38.9 & 43.1 & 34.7 & 33.0 & 31.5 & 40.6 & 63.0 & 119.7 & 49.0 \\
\hline $\mathrm{CHCl}_{3}$ & 42.5 & 48.4 & 39.0 & 40.9 & 39.0 & 27.1 & 64.4 & 95.2 & 47.7 \\
\hline $\mathrm{CCl}_{4}$ & 40.0 & 50.2 & 41.5 & 40.1 & 46.1 & 28.1 & 50.7 & 38.8 & 20.6 \\
\hline ter-but & - & 51.2 & 47.2 & 51.5 & 60.1 & - & - & 123.6 & 45.0 \\
\hline DEE & 67.5 & 53.9 & 42.3 & 47.8 & 49.9 & - & - & 99.3 & 39.4 \\
\hline Me-Ac & 58.3 & 54.2 & 43.6 & 49.0 & 45.0 & 60.5 & 65.1 & 99.1 & 89.4 \\
\hline THF & 72.9 & 56.8 & 48.0 & 52.3 & 52.9 & 35.1 & 52.7 & 73.3 & 36.3 \\
\hline Dioxane & - & 62.9 & 53.2 & 54.6 & 41.6 & 18.1 & 36.0 & 21.1 & - \\
\hline
\end{tabular}

Table 6 - Determination of Organic Thickness from the Intensity of the Si 2p Peak

\begin{tabular}{|c|c|c|}
\hline \multirow{2}{*}{ Ormosil } & \multicolumn{2}{|c|}{$\mathrm{Al} \mathrm{K \alpha}$} \\
\cline { 2 - 3 } & $\mathrm{I}_{\mathrm{d}} /$ counts & $\mathrm{d} / \mathrm{nm}$ \\
\hline methyl & 4500 & 2.0 \\
\hline ethyl & 3900 & 2.2 \\
\hline vinyl & 3900 & 2.2 \\
\hline phenyl & 2400 & 3.0 \\
\hline $\mathrm{SiO}_{2}$ & $\mathrm{I}_{\infty}=16000$ & $\lambda_{\mathrm{Si}}=3.2$ \\
\hline
\end{tabular}


Table 7 - Comparison of C 1s, O 1s Si 2p Peak Intensity

\begin{tabular}{|c|c|c|c|c|c|c|c|c|c|c|c|c|}
\hline Ormosil & \multicolumn{5}{|c|}{$\mathrm{Al} \mathrm{K \alpha}$} & \multicolumn{7}{|c|}{$\mathrm{Mg} \mathrm{K} \alpha$} \\
\hline & $\begin{array}{c}\mathrm{C} \\
\mathrm{at} \%\end{array}$ & $\begin{array}{c}\mathrm{O} \\
\mathrm{at} \%\end{array}$ & $\begin{array}{c}\mathrm{Si} \\
\mathrm{at} \%\end{array}$ & $\begin{array}{l}\mathrm{Na} \\
\mathrm{at} \%\end{array}$ & $\begin{array}{l}\mathrm{C} / \\
\mathrm{Si}\end{array}$ & $\begin{array}{c}\mathrm{C} \\
\mathrm{at} \%\end{array}$ & $\begin{array}{c}\mathrm{O} \\
\mathrm{at} \%\end{array}$ & $\begin{array}{c}\mathrm{Si} \\
\mathrm{at} \%\end{array}$ & $\begin{array}{l}\mathrm{Al} \\
\mathrm{at} \%\end{array}$ & $\begin{array}{l}\mathrm{Na} \\
\mathrm{at} \%\end{array}$ & $\begin{array}{c}\mathrm{N} \\
\mathrm{at} \%\end{array}$ & $\mathrm{C} / \mathrm{Si}$ \\
\hline HDKN20 & 4.0 & 73.2 & 22.8 & - & 0.2 & 8.4 & 63.5 & 25.7 & 0.9 & - & - & 0.3 \\
\hline methyl & 26.6 & 58.7 & 14.7 & - & 2.3 & 33.4 & 45.6 & 20.2 & - & - & 0.8 & 1.7 \\
\hline ethyl & 40.1 & 43.5 & 16.4 & - & 2.4 & 44.9 & 37.0 & 15.2 & 1.9 & 0.5 & 0.5 & 3.6 \\
\hline vinyl & 42.1 & 42.2 & 15.4 & 0.3 & 2.1 & 46.1 & 41.2 & 10.8 & - & 1.0 & 0.9 & 4.7 \\
\hline phenyl & 65.9 & 23.1 & 11.0 & - & 5.7 & 64.6 & 24.8 & 9.7 & - & - & 0.9 & 6.6 \\
\hline
\end{tabular}

Table 8 - FT-IR Assignments for Figure 3

\begin{tabular}{|c|c|c|c|c|c|}
\hline \multicolumn{2}{|c|}{ Silica } & \multicolumn{2}{|c|}{ Organo-silica bonding } & \multicolumn{2}{|c|}{ Silanol interactions } \\
\hline $\mathrm{cm}^{-1}$ & Description & $\mathrm{cm}^{-1}$ & Description & $\mathrm{cm}^{-1}$ & Description \\
\hline $1225-1200$ & \multirow[t]{3}{*}{ Bulk silica } & $3080-3030$ & $\mathrm{Si}-\mathrm{Ph}$ & $3700-3200$ & silanols \\
\hline $1175-1150$ & & $1290-1240$ & $\mathrm{Si}-\mathrm{CH}_{3}$ & $\sim 3650$ & $\begin{array}{l}\text { Perturbed silanol } \\
\text { groups (due to inter- } \\
\text { particle contact) }\end{array}$ \\
\hline $1100-1075$ & & $1250-1220$ & $\mathrm{Si}-\mathrm{C}_{2} \mathrm{H}_{5}$ & $\sim 3620$ & Isolated silanol groups \\
\hline$\sim 1085$ & \multirow[t]{2}{*}{$\begin{array}{l}\text { Long chain } \\
\text { silica }\end{array}$} & & & $\sim 3550$ & $\begin{array}{l}\text { Maximum absorbance } \\
\text { of general silanol } \\
\text { band }\end{array}$ \\
\hline$\sim 1025$ & & & & \multirow[t]{2}{*}{$\sim 3450$} & \multirow{2}{*}{$\begin{array}{l}\text { Silanol groups } \\
\text { participating } \\
\text { hydrogen bonding (to } \\
\text { other silanol groups }\end{array}$} \\
\hline$\sim 1050$ & $\begin{array}{l}\text { Short chain } \\
\text { silica }\end{array}$ & & & & \\
\hline
\end{tabular}


Table 9 - Classification of Acid-Base Interactions

Source: Jensen ${ }^{24}$ (Table 2)

\begin{tabular}{|c|c|c|c|c|c|}
\hline & \multicolumn{3}{|c|}{ Acceptor orbital } \\
\hline & & & \multirow[b]{2}{*}{$\mathrm{n}$} & \multicolumn{2}{|c|}{$\mathrm{a}$} \\
\hline & & & & $\sigma^{*}$ & $\pi^{*}$ \\
\hline \multirow{3}{*}{$\begin{array}{l}\text { Donor } \\
\text { orbital }\end{array}$} & & $\mathrm{n}$ & $n-n$ & $n-\sigma^{*}$ & $n-\pi^{*}$ \\
\hline & \multirow[t]{2}{*}{$\mathrm{b}$} & $\sigma$ & $n-\sigma$ & $\sigma-\sigma *$ & $\sigma-\pi *$ \\
\hline & & $\pi$ & $n-\pi$ & $\pi-\sigma^{*}$ & $\pi-\pi *$ \\
\hline
\end{tabular}

Table 10 - Functionalities of Polyester and Silicas and Associated Acido-basic Characteristics

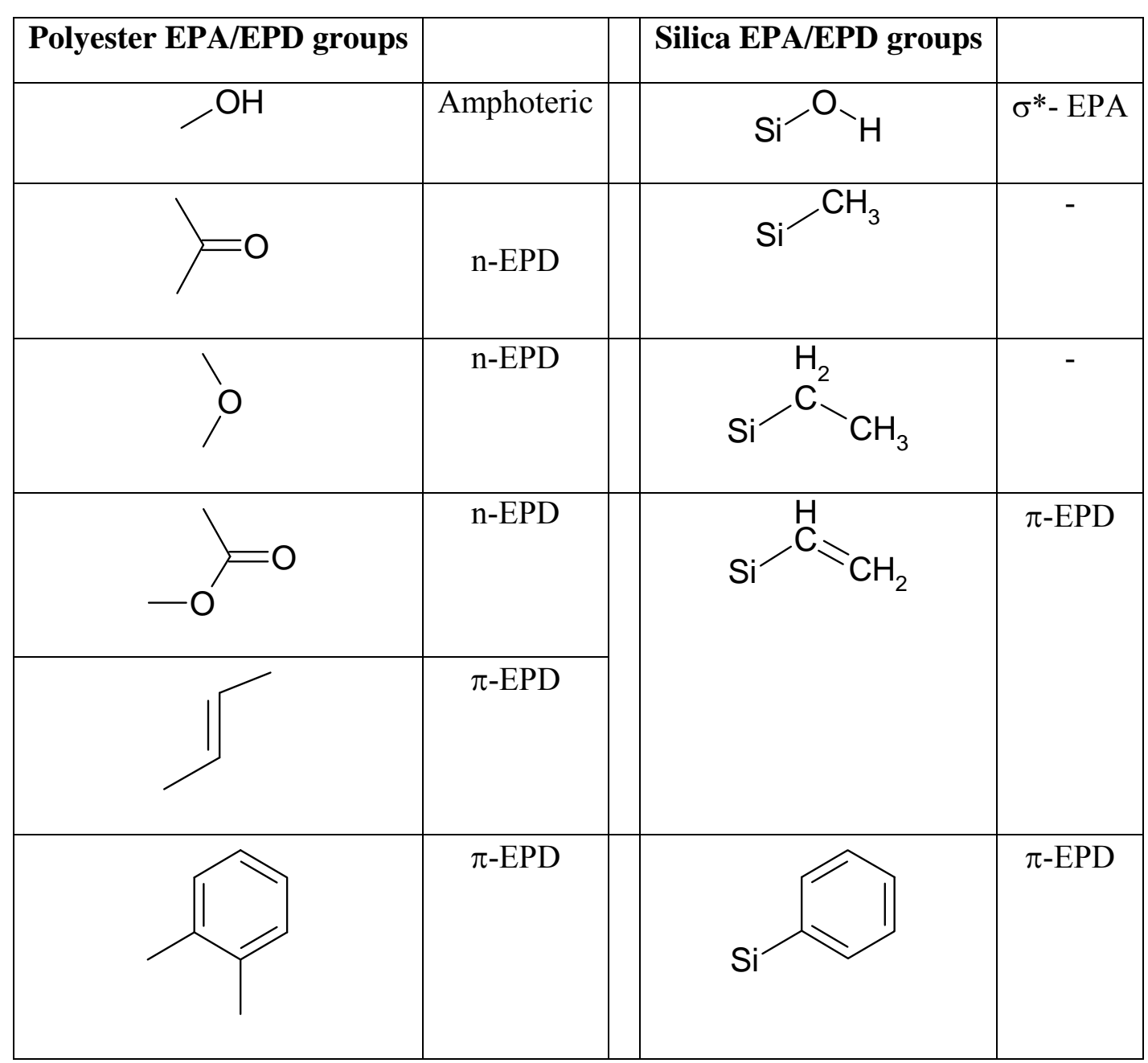




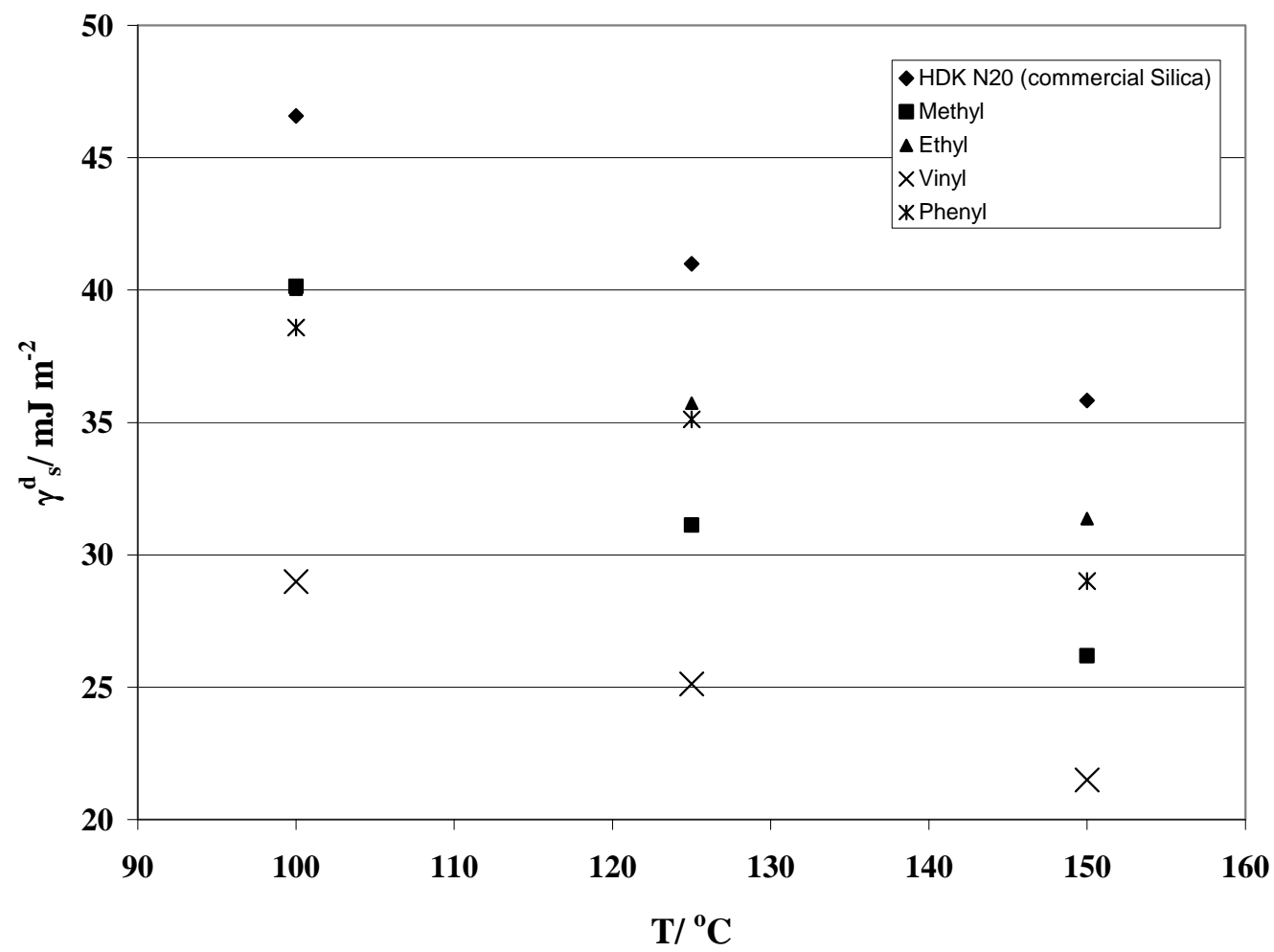

Figure $1-\gamma_{s}^{d}$ of Ormosils and a Commercial Silica as a Function of Temperature 

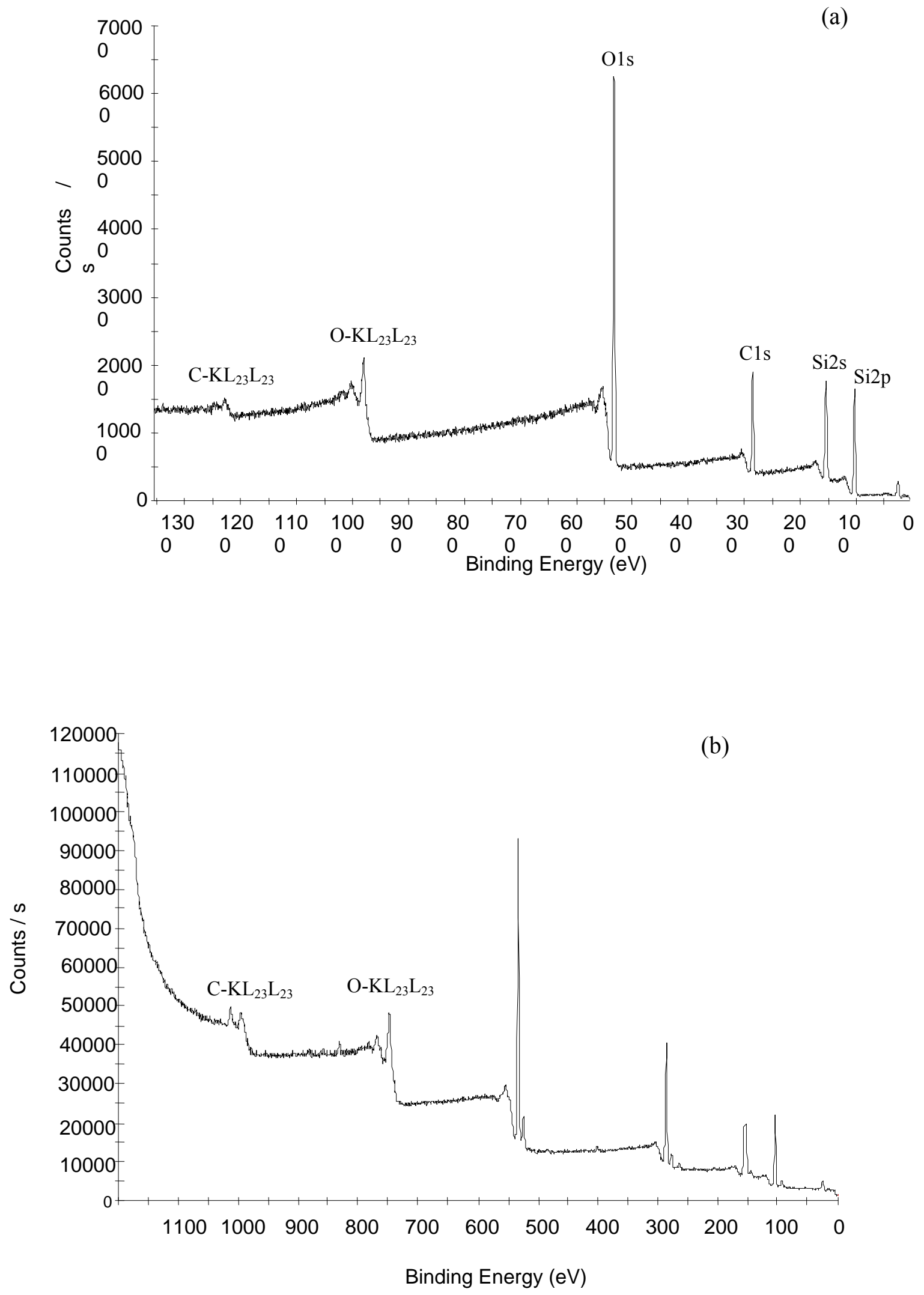

Figure 2 - XPS Survey Spectra of Methyl Modified Silica Comparing (a) Al Ka and (b) Mg Ka Sources 

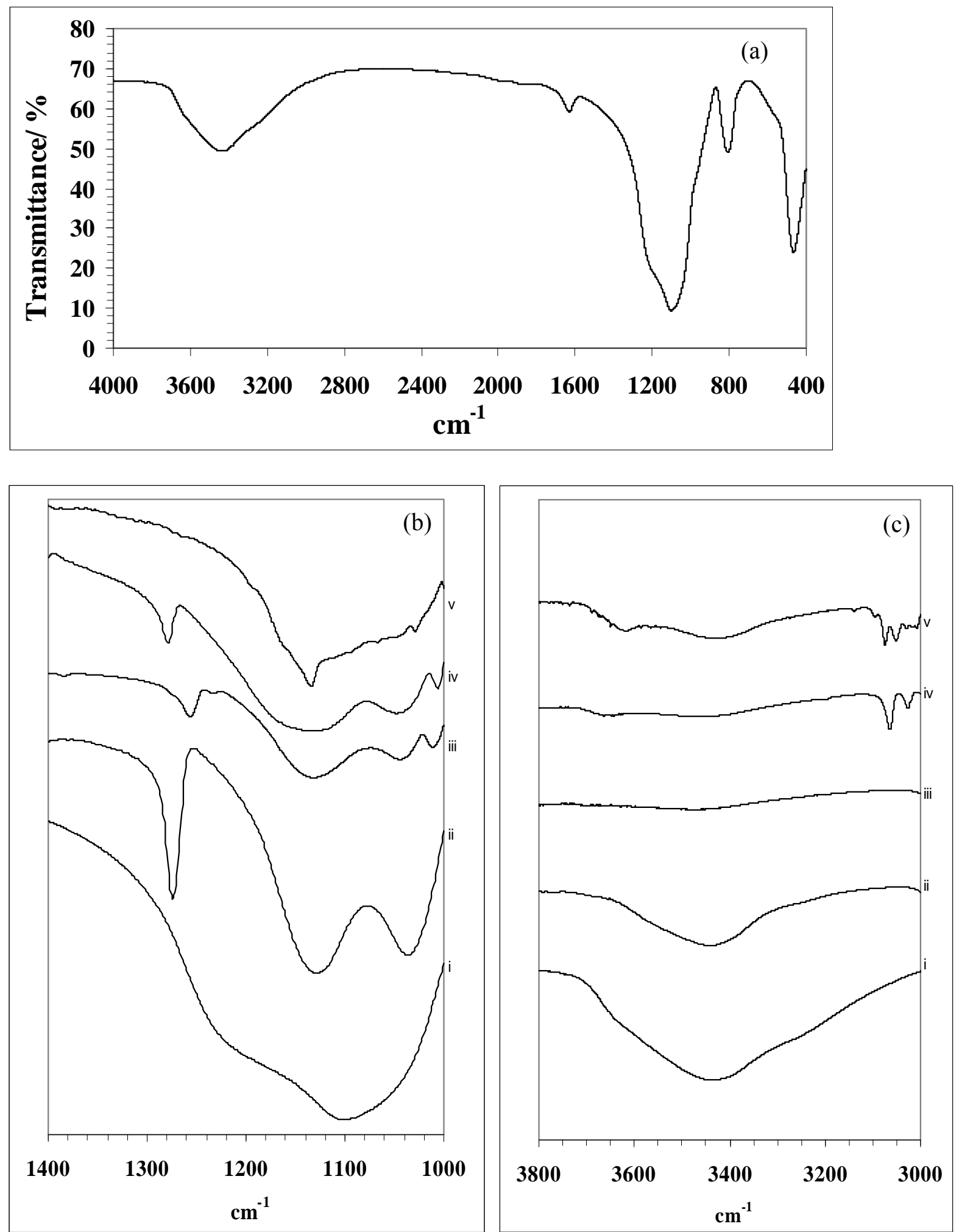

Figure 3 - IR Spectrum (a) commercial silica (b) comparison of commercial silica with ormosil for $1000-1400 \mathrm{~cm}^{-1}$ and (c) comparison of commercial silica with ormosil for $3000-3800 \mathrm{~cm}^{-1}$

(i) commercial silica (ii) methyl modified (iii) ethyl modified (iv) vinyl modified (v) phenyl modified 


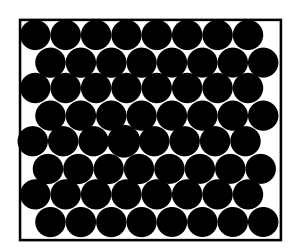

(a)

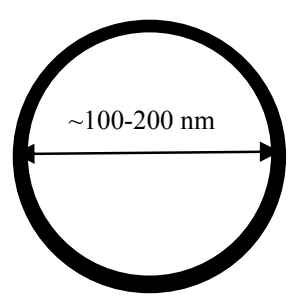

(b)

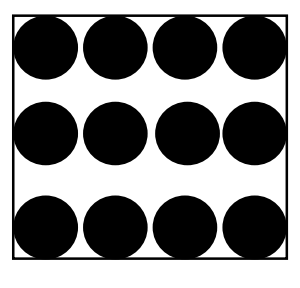

(c)

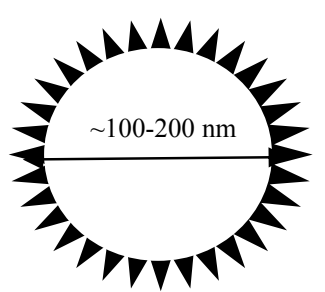

(d)

Figure 4 - Comparison of the surfaces of $(a, b)$ methyl, ethyl and vinyl modified silicas and $(c, d)$ phenyl modified silica. 


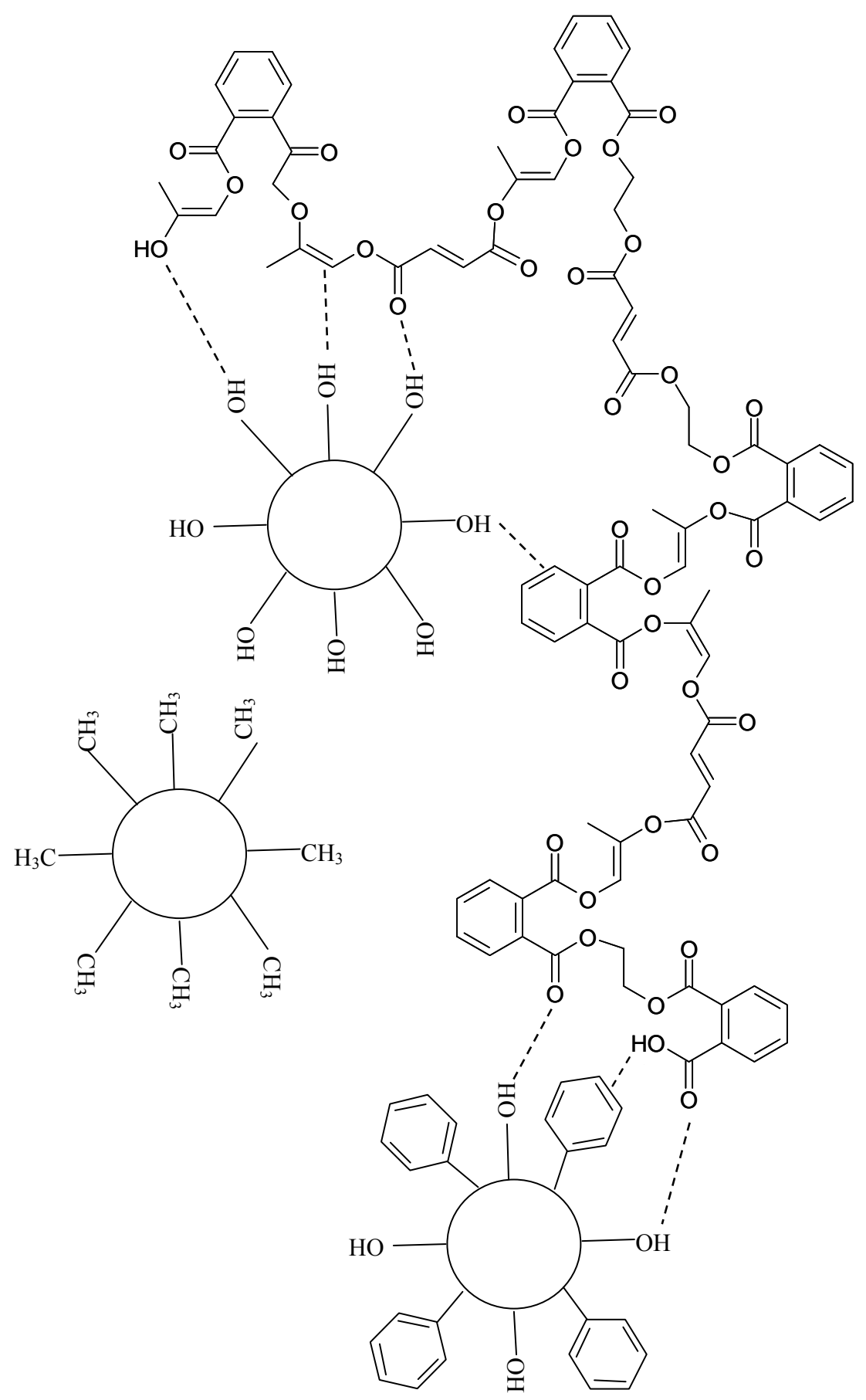

Figure 5 - Schematic of the possible interactions between the polyester and the commercial silica, phenyl modified silica and methyl silica 


\section{REFERENCES}

1. Bescher, E.; Mackenzie J.D. Materials Science and Engineering C 1998, 6, 145-154

2. Lebeau, B.; Sanchez, C. Curr. Opinion Solid State Mater. Sci. 1999, 4, 11-23

3. Bekiari, V. Proceedings of the $11^{\text {th }}$ European Conference on Composite Materials, 2004, C020

4. Arkhireeva, A.; Hay, J.N. J. Mat. Chem. 2003, 13, 3122-3127

5. Arkhireeva, A.; Hay, J.N.; Manzano, M. Chem. Mat. 2005, 17, 875-880

6. Jesson, D.A.; Abel M.-L.; Arkhireeva, A.; Hay, J.N.; Smith. P.A.; Watts, J.F. Surf. Interface Anal. 2004; 36, 765-768

7. Jesson, D.A.; Arkhireeva, A.; Hay, J.N.; Smith. P.A.; Watts, J.F. $11^{\text {th }}$ European Conference on Composite Materials (Proceedings) 2004, C086

8. Papirer, E.; Balard, H.; Vidal, A. Eur. Polym. J. 1988, 24, 783-790

9. Vickers, P.E.; Watts, J.F.; Perruchot, C.; Chehimi, M.M. Carbon, 2000, 38, 675-689

10. van Asten, A.; van Veenendaal, N.; Koster, S. J. Chromatogr. A, 2000, 888, 175-196

11. Perruchot, C.; Chehimi, M.M.; Delamar, M.; Lascelles SF; Armes S.P. J. Colloid Interface Sci. 1997, 193, 190-199

12. Papirer, E.; Brendle, E.; Ozil, F.; Balard, H. Carbon 1999, 37, 1265-1274

13. Andrzejewska, E.; Voelkel, A.; Andrzejewska, M.; Maga, R. Polymer, 1996, 37, 4333-4344

14. Al-Saigh, Z.Y.; Munk, P. Macromolecules 1984, 17, 803-809

15. Kontominas, M.G.; Gavara, R.; Giacin, J.R.; Eur. Polym. J. 1994, 30, 265-269

16. Dorris, G.M.; Gray D.G. J. Colloid Interface Sci. 1980, 77, 353-362 
17. Roe, R.-.J, J. Phys. Chem. 1968; 72: 2013-2017

18. .Saint Flour, C.; Papirer, E., Ind. Eng. Chem.: Prod. Res. Dev. 1982, 21, 666-669

19. Cross, Y.M.; Dewing, J. Surf. Interface Anal. 1979, 1, 26-31

20. Watts, J.F.; Carney, T.J. in Powder Metallurgy: An Overview, ed. I. Jenkins and J.V. Wood, Institute of Metals, 1991, 76-99

21. Morrow, B.A.; Gay, I.D. in Adsorption on Silica Surfaces, ed. E. Papirer, Marcel Dekker Inc., 2000, 9-33

22. Chehimi, M.M.; Abel, M.-L.; Sahraoui, Z.; Fraoua, K.; Lascelles, S.F.; Armes, S.P. Int. J. Adhes. Adhes, 1997, 17, 1-8

23. Percy, M.J.; Amalvy, J.I.; Barthet, C.; Armes, S.P.; Greaves, S.J.; Watts, J.F.; Wiese, H. J. Mat. Chem., 2002, 12, 697-702

24. Jensen, W.B. Chemtech, 1982, 12, 755-764

25. Leadley, S.R.; Watts, J.F. J. Adhes. 1997,60, 175-196

26. Chehimi, M.M.; Watts, J.F., Jenkins, S,N., Castle, J.E. J. Mat. Chem. 1992, 2, 209-215 